Editorial

\title{
Donald Hunter 1898-1978: Editor BJIM 1944-50
}

Donald Hunter, Bernardino Ramazzini, and Charles Turner Thackrah were physicians with a compelling interest in occupational disease. They stand out as pioneers in a discipline that has never been in the main stream of medicine. What made them take this unusual and financially unprofitable step? In the 18th century, Ramazzini was inspired by the opportunities it offered for new observations and a sympathy for the common people. A 100 years later, Thackrah concluded that humanity and science demanded an examination into the state of our manufactories. Hunter was inspired by his frequent contact with patients adversely affected by their work, by his concern for the underprivileged, and above all by his interest in being a medical detective.

Donald Hunter's concern for those working in dangerous trades was, no doubt, stimulated by his upbringing in the East End of London as one of four distinguished brothers, sons of a post office engineer and a remarkable mother to whom he ascribed his own success and that of his siblings.

He went to the London Hospital Medical School in 1915 , leaving temporarily in 1917 to join the Royal Navy. He served as a surgeon probationer in a destroyer in the famous St George's Day attack on Zeebrugge. He qualified in 1920 and obtained his MD two years later with a thesis on steatorrhoea. In 1926 he went to Harvard Medical School as a research fellow and worked with $\mathrm{J} C \mathrm{Aub}$ and A S Minot on lead poisoning, which aroused his interest in industrial toxicology and bone metabolism; the second of which was the main subject of his early publications. Within 10 years he had made his mark as a brilliant general physician and an authority on bone diseases, endocrinology, diabetes, and blood diseases. He was appointed consultant physician to the London Hospital at the early age of 29 and soon built up a substantial private practice that satisfied neither his intellectual curiosity nor his missionary zeal to impart his enthusiasm for medicine and to fire others with his unquenchable inquisitiveness.

He became a joint author of Hutchison's Clinical Methods, which was essential reading for medical students and an invaluable reminder of the basics of clinical medicine for MRCP examinees. He will be remembered as a brilliant lecturer with a caustic wit, sparing no one, not even senior colleagues. His teaching on the wards and in his outpatient "circus" was always stimulating, full of surprises and entertaining anecdotes. Although it was occasionally repetitive and rigged, Hunter exploited his gifts as a showman to impress on his students the privilege and the responsibilities of being in medicine.

In the 1930s and '40s, Hunter's researches were increasingly devoted to industrial toxicology, the subject of his Croonian lecture to the Royal College of Physicians in 1942. His investigations included occupational neuropathies from exposure to organic mercury compounds and tri-orthocresyl phosphate, inorganic mercury, and lead. He became a key figure during the rapid development of occupational medicine in the 1940s.

In 1943 Hunter was appointed Director of the new MRC Department of Industrial Medicine at the London Hospital and became the first editor of the British fournal of Industrial Medicine assisted by two experienced industrial medical officers. The $B$ fIM published papers of mixed quality covering a wide range of subjects, such as training nurses, eye testing, nutrition, and descriptions of different types of medical services operating in industry. The pot boilers put the journal on its feet financially and were useful to industrial medical officers, mostly inexperienced and untrained as we all were at that time. Demand for the journal outstripped supply but it did not fulfil Hunter's ambition to start a scientific journal. After two years he took editorial control helped by a committee with academics such as Tony Bradford Hill, Thomas Bedford, Frederick Bartlett, and Ronald Lane. They began the journal's metamorphosis into a scientific publication with original papers, critical reviews, and abstracts. Gaps left by the loss of general articles were filled by an increasing output from Hunter's department at the London Hospital and new MRC units. Nevertheless, 1950 was a critical year in the life of the journal because of an acute shortage of original papers and Hunter was suffering from a bleeding peptic ulcer. When I visited him in hospital, he had been forbidden to do any work. He was very pale but there was the usual twinkle in his eye as he read a medical journal concealed behind the pages of Punch. It was then that he asked me to edit the BfIM during his illness. Gradually the journal's problems were 
resolved by contributions not only from MRC units but also from newly established university departments of occupational health with a trickle from other countries. After a false start Hunter set the $B f I M$ on the right lines and his successors have made it an international journal of the highest standing with the bulk of papers coming from academic centres outside the United Kingdom. With the backing of his MRC unit, Hunter extended his researches to include a variety of health hazards such as bagassosis, silicosis in Cornish tin miners, Reynaud's phenomenon from exposure to vibrating tools, asthma from platinum salts, and fluorosis in humans and cattle exposed to fluorides. It was, however, as a writer and teacher that he made his most important and lasting contribution to occupational medicine. His Diseases of Occupations was first published in 1955. It was acclaimed a classic and by 1978 had achieved a sixth edition. With its chapters on the industrial revolution and the social evils and reforms of the 19 th and 20th centuries it was flavoured with history and passages from fiction, sometimes irrelevant but always entertaining even for those who knew nothing about occupational medicine. Diseases of Occupations was an artist's impression of his favourite subject, painted in vivid colours, not in respectable pastel shades. Although it lacked the balance and accuracy of a book compiled by several authors covering special fields, it gained immeasurably in its readability and in the impact it made on the medical profession.

It is not by chance that many of Hunter's former students have gone on to hold key positions in occupational medicine. John Gilson, who directed the MRC Pneumoconiosis Unit, wrote this appreciation of Donald Hunter: "I owed him a lot. My first job as a student was on his firm-a very stimulating start to a medical career. I suppose indirectly I owe to him my whole very interesting and enjoyable life in occupational medicine". For a different reason I owe my career in occupational medicine to Donald Hunter. I had applied for a job as a medical officer with ICI so that I could get married. I knew nothing about industrial medicine, but, by chance, I read his article in the current number of the $B M F$ on Prevention of disease in industry 1 just before I went to the interview. I was told by the other candidate that he had been promised the job. I quoted Hunter to the selection panel without disclosing the source of my newly found knowledge and got the job. This temporary assignment opened the door to a permanent career. A few years later when I was secretary of the MRC's Industrial Health Research board, which entailed organising but not really doing any research, I was influenced by Hunter's tremendous enthusiasm. He strongly advised me to leave my administrative post and become fully involved in academic occupational medicine.

After his retirement from the London Hospital
Donald Hunter continued to lecture on occupational diseases to students at Middlesex and Guy's Hospitals and to postgraduates at the London School of Hygiene and Tropical Medicine. Through his dynamic teaching and writings, he influenced doctors to become occupational physicians and taught many more, whatever their field of practice, to pay heed to a patient's work. Whereas Ramazzini in De Morbis Artificum ${ }^{2}$ advised physicians to ask the patient or his relatives, "What occupation does he follow?" Hunter in his classic work $^{3}$ recommended a more penetrating enquiry: "Ask him the name of his trade, the processes employed, the tools used, and the substances handled. The name he gives to his job may be an obvious euphemism. If he tells you he's a salvage officer he means a dustman... Whether he be a fish hobbler... trolloper or whammeler, he will respond to your detailed questions if only you are firm and tactful and show appreciation of his skill." "No doctor can be expected to be familiar with the details of all occupations and every working environment, but at least he should take the opportunity to study those industries which fall within the area of his practice... there are few surer and quicker means of gaining a patient's confidence than the display of an intelligent knowledge of his job."

"Where an occupational disease is suspected, ask whether any similar illness has occurred in a fellow workman. The answer to this question can provide valuable evidence of an occupational cause of a disease and may be life saving."

In most countries the majority of people at work are not covered by in plant occupational health services. Even where there are such services a sick worker often seeks advice first from the family doctor or, in an emergency, from a hospital. Thus a general practitioner or hospital doctor can play a vital part in identifying work related illnesses. Donald Hunter made it clear through his writings and teaching that any doctor who looks after patients must be aware of the influence that work has on health. He has set an example that is now followed by other medical schools of teaching occupational medicine as an integral part of primary health care.

I thank Dr A J Daly for providing information on Donald Hunter's early career and teaching at the London Hospital and my family for helpful criticism.

$11 c$ Prior Bolton Street, RICHARD SCHILLING London N1 $2 \mathrm{NX}$

1 Hunter D. Prevention of disease in industry. $B M 1 \mathcal{F}$ 1937;1:700-3.

2 Ramazzini B, De Morbis Artificum. 2nd edition translated by WC Wright. Chicago: 1940, University Press.

3 Hunter D. Diseases of occupations. 6th ed. Sevenoaks: Hodder and Stoughton, 1978. 